
work is properly cited

\title{
DEPRESSION AND ITS PHARMACOLOGICAL MANAGEMENT: A CRITICAL REVIEW
}

\author{
1*Dr. Nagapati P Bhat, ${ }^{2}$ Dr. Preethishree P,
}

\author{
${ }^{1}$ Assistant Professor, Department of Pharmacology, Yenepoya Medical College, Yenepoya University, Mangalore- \\ 575018 \\ ${ }^{2}$ III year Postgraduate, Department of Microbiology, K S Hegde Medical Academy, Nitte University, Mangalore- \\ 575018
}

Received 20 May 2015; Review Completed 23 June 2015; Accepted 08 July 2015, Available online 15 July 2015

\begin{abstract}
Depression is considered as an affective disorder characterized primarily by change of mood. It is associated with significant socioeconomic problems, morbidity and mortality. The prevalence of major depression in the general population is estimated at $5 \%$ in world population. Prevalence ranges from $9 \%$ in ambulatory medical patients to $30 \%$ in hospitalized patients. According to the World Health report approximately 450 million people suffer from a mental or behavioral disorder, yet only a small minority of them receives even the most basic treatment. Currently, the available anti-depressant agents are associated with unwanted side effects and have their own limitations. An increasing number of herbal products have been introduced into psychiatric practice, as alternative or complementary medicines. The added advantages of indigenous medicinal treatment would include its complementary nature to the conventional treatment making latter safer, well tolerated and economical remedy for depressive disorders.
\end{abstract}

Key words: Depression, Anti-depressants, Pharmacotherapy, Side effects

\section{INTRODUCTION:}

Depression is a common mental disorder, characterized by sadness, loss of interest or pleasure, feelings of guilt or low self-worth, disturbed sleep or appetite, low energy and poor concentration. ${ }^{1}$ Depression has a worldwide prevalence in various forms, of $12-20 \%$. The World Health Organization (WHO) has ranked depression fourth in a list of the most urgent health problems worldwide. Depression is the leading cause of disability as measured by Years Lived with Disability (YLDs) and the 4th leading contributor to the global burden of disease as measured by Disability Adjusted Life Years (DALYs) in 2000. It will become the second leading cause of premature death or disability worldwide by the year 2020. At its worst, it can lead to suicide, a tragic fatality associated with the loss of about 850,000 lives every year globally. In India the prevalence of depression is $31.2 / 1000$ population. $^{2}$

\section{DIAGNOSTIC CRITERIA: ${ }^{3}$}

The DSM-IV TR (Text Revision of the Fourth Edition of the Diagnostic and Statistical Manual of Mental Disorders, 2000) of the American Psychiatric Association lists the following criteria, which need to be fulfilled to make a diagnosis of a major depressive episode.

A. Five or more of the following symptoms have been present during the same 2-week period and represent a change from the previous functioning; at least one of the symptoms is either

(1) depressed mood or (2) loss of interest or pleasure.

Note: Do not include symptoms that are clearly due to a general medical condition, or mood-incongruent delusions or hallucinations.

1) Depressed mood most of the day, nearly every day, as indicated by either subjective report (e.g., feels sad or empty) or observation made by others (e.g., appears tearful).

Note: In children and adults, can be irritable mood.

2) Markedly diminished interest or pleasure in all, or almost all activities, most of the day, nearly every day (as indicated by either subjective account or observation made by others).

*Corresponding author: Dr. Nagapati. P. Bhat, Assistant Professor, Department of Pharmacology, Yenepoya Medical College, Yenepoya University, Mangalore, India-575018 Phone number: 09480710120, Email: npbhat17@gmail.com 
3) Significant weight loss when not dieting or weight gain (e.g., a change of $>5 \%$ body weight in a month) or increase or decrease in appetite nearly every day.

Note: In children, consider failure to make expected weight gains.

4) Insomnia or hypersomnia nearly every day.

5) Psychomotor agitation or retardation nearly every day (observable by others, not merely subjective feelings of restlessness or being slowed down).

6) Fatigue or loss of energy nearly every day.

7) Feeling of worthlessness or excessive inappropriate guilt (which may be delusional) nearly every day (not merely self-reproach or guilt about being sick).

8) Decreased ability to think or concentrate, or indecisiveness, nearly every day (either by subjective account or as observed by others).

9) Recurrent thoughts of death (not just fear of dying), recurrent suicidal ideation without a specific plan, or a suicide attempt or a specific plan for committing suicide.

B. The symptoms do not meet criteria for a mixed episode.

C. The symptoms cause clinically significant distress or impairment in social, occupational or other important areas of functioning.

D. The symptoms are not due to the direct physiological effects of a substance (e.g., a drug of abuse, a medicine) or a general medical condition (e.g., hypothyroidism).

E. The symptoms are not better accounted for by bereavement, i.e., after the loss of a loved one, the symptoms persist for longer than 2 months or are characterized by marked functional impairment, morbid preoccupation with worthlessness, suicidal ideation, psychotic symptoms, or psychomotor retardation.

\section{TYPES OF DEPRESSION: ${ }^{4}$}

1. Unipolar depression: - About $80 \%$ of cases, in which mood swings in one direction only (either depression with a feeling of worthlessness or depression with groundless irritability).

2. Bipolar depression (or manic depressive psychoses, MDP):- About 20\% cases, characterized by cyclic manifestation of depression followed by mania.

\section{MANAGEMENT OF DEPRESSION:}

\section{Pharmacotherapy:}

Iproniazid a derivative of isoniazid, a nonselective monoamine oxidase inhibitor (MAO) inhibitor was the first antidepressant to be used clinically in the mid 1950's. Subsequently other MAO inhibitors phenelzine and isocarboxazid were introduced. Tranylcypromine, structurally related to amphetamine was first MAO inhibitor unrelated to hydrazine to be discovered. Later the selective MAO-A inhibitors like clorgyline, moclobemide and MAO-B inhibitors like selegiline were introduced. ${ }^{5}$
In the late 1940s a series of more than 40 iminodibenzyl derivatives were synthesized for possible use as antihistamines, sedatives, analgesics, and antiparkinsonism drugs. One of these was imipramine, a dibenzazepine compound which was found to have remarkable effect on depressed patients. ${ }^{6}$ Following this more selective serotonin reuptake inhibitors were developed in the early 1970. These developments were paralleled by the identification of compounds with selectivity for norepinephrine reuptake and along with others effective against both serotonin and norepinephrine reuptake. ${ }^{7}$

The currently used antidepressant drugs are classified as follows: ${ }^{8}$

\section{MAOIS}

* Irreversible agents:

I. Phenelzine II. Tranylcypromine III. Isocarboxazid IV. Selegiline

\section{* Reversible agents:}

I. Moclobemide

\section{Reuptake Inhibitors:}

1. Serotonin and Norepinephrine reuptake inhibitors

\section{* Older agents (TCAs)}

I. Amitriptyline II. Dothiepin III. Clomipramine IV. Imipramine

\section{* Newer agents (non-TCAs)}

I. Venlafaxine II. Milnacipran III. Bupropion IV. Duloxetine

\section{Nonselective norepinephrine-reuptake inhibitors}

I. Desipramine II. Nortriptyline III. Maprotiline

\section{Selective serotonin-reuptake inhibitors (SSRIs)}

I. Fluoxetine II. Paroxetine III. Sertraline IV. Fluvoxamine V. Citalopram

VI. Escitalopram

4. Selective norepinephrine-reuptake inhibitors (NRIs)

I. Reboxetine

\section{Mixed-action newer agents}

I. Mirtazapine II. Mianserin III. Nefazodone IV. Trazodone

\section{Augmenting or Adjunctive Drugs}

\section{A. Mood stabilizers}

I. Lithium II. Lamotrigine III. Valproic acid

\section{B. Antipsychotic agents}

* Typical

I. Chlorpromazine II. Haloperidol

\section{* Atypical}


I. Clozapine II. Olanzapine III. Risperidone IV. Quetiapine V.Aripiprazole

\section{Ziprasidone}

\section{Thyroid supplement}

I. Thyroxin.

\section{MECHANISM OF ACTION OF VARIOUS ANTIDEPRESSANT DRUGS:}

\section{MAO Inhibitors:}

Monoamine oxidase inhibitors (MAOIs) were the first class of anti depressants in clinical use. These drugs reversibly or irreversible block monoamine oxidase enzyme. MAO regulates the metabolic degradation of catecholamines, serotonin and other endogenous amines in the CNS and peripheral tissues. Hepatic MAO has a crucial defensive role in inactivating circulating monoamines or compounds, such as the indirect-acting sympathomimetic tyramine, that are ingested or originate in the gut and are absorbed into the portal circulation. Inhibition of this enzyme system by MAO inhibitors causes a reduction in metabolism and a subsequent increase in the concentration of biogenic amines. Of the two major molecular species, MAO-A preferentially deaminates epinephrine, norepinephrine and serotonin whereas MAO-B metabolizes phenylethylamine. Dopamine and tyramine are metabolized by both MAO isozymes. Clorgyline and moclobemide selectively inhibit MAO$A$ and selegiline selectively inhibit MAO-B. Phenelzine, tranylcypromine and isocarboxazid inhibit both MAO-A and MAO-B. Experimentally, selective MAO-A inhibitors are thought to be more effective in treating major depression than type B inhibitor.

MAOIs are not considered to be first-line antidepressant medications because of their extensive side-effect profile. They have potent hypotensive effects. This is particularly important when treating elderly patients. Other common side effects are weight gain, sedation, insomnia, restlessness and confusion. Anorgasmia is fairly common with therapeutic doses of some MAOIs. MAOIs may cause dangerous interactions with certain foods (cheese reaction) and with serotonergic drugs. ${ }^{9}$

Despite their side effect profile MAOIs can be useful in patients resistant to tricyclic antidepressants. ${ }^{10}$ MAOIs appear to be superior to tricyclic agents for people with depression charecterized by extreme fatigue or extreme psychological sensitivity to rejection or failed relationships. ${ }^{11}$ Several short acting selective inhibitors of MAO-A e.g.; brofaromine moclobemide and toloxate are being investigated. They are less likely to potentiate the pressor action of tyramine and other indirect acting sympathomimetic amines than non selective irreversible MAO inhibitors.

\section{Reuptake Inhibitors:}

1. Serotonin and Norepinephrine reuptake inhibitors:

* Older agents (TCAs):
The tricyclic antidepressants were discovered in the 1950s. They are dibenzazepine derivatives. They were called tricyclics because their organic chemical structure contains three rings-two benzene rings joined by a seven-member ring containing nitrogen, oxygen or only carbons. Structurally they differ from phenothiazines in that the sulphur is replaced by ethylene linkage. Imipramine was initially tested as an antipsychotic compound (its chemical is closely related to the antipsychotic chlorpromazine), but was found to have antidepressant and not antipsychotic properties. The actions of tricyclic antidepressants include inhibiting the reuptake of norepinephrine predominantly and variable blockade of serotonin transport. ${ }^{12}$ In addition, TCAs have other actions: blockade of muscarinic cholinergic receptors, blockade of $\mathrm{H}_{1}$ histamine receptors and blockade of $\alpha-1$ adrenergic receptors and to some extent $\alpha-2$ receptors. Initially the pre-synaptic $\alpha-2$ and $5-\mathrm{HT}_{1}$ are activated by increase amount of norepinephrine and serotonin resulting in decreased firing of locus ceruleus and raphe neurons. ${ }^{13}$ On long term administration there is desensitizing of these receptors and induction of other adaptive changes in the number and sensitivity of pre and post synaptic noradrenergic and serotonergic receptors as well as amine turnover in brain which leads to enhanced noradrenergic and serotonergic transmission. Tricyclic antidepressants also block sodium channels in the heart and brain, which can cause cardiac arrhythmias and cardiac arrest in overdose, as well as seizures. The TCAs do not block dopamine transport but they may facilitate effects of dopamine indirectly by inhibiting the nonspecific transport of dopamine into noradrenergic terminals in cerebral cortex. Tricyclic antidepressants also can desensitise $\mathrm{D}_{2}$ dopamine autoreceptors through uncertain mechanisms and with uncertain behavioural contributions. ${ }^{14}$ The tricyclic antidepressants are less commonly used as first line antidepressants because of their side effect profile. At therapeutic doses, all tricyclic antidepressants are considered effective in uncomplicated non delusional depression. They tend to have dose related side effects such as anticholinergic and orthostatic effects, as well as sedation, weight gain and sexual dysfunction. In addition, tricyclic antidepressant users have a high risk of myocardial infarction and arrhythmias.

\section{* Newer agents (Non Tricyclic agents):}

Venlafaxine, duloxetine and milnacipran are serotonin-norepinephrine reuptake inhibitors which inhibit monoamine transporters more selectively than tricyclic antidepressants and without the cardiac conduction effects that can occur with tricyclic agents. ${ }^{15}$ Venlafaxine also weakly inhibits dopamine reuptake. It is reported to have little affinity for muscarinic, histaminergic or $\alpha-1$ adrenergic receptors in vitro. It has faster onset of action with minimal side effects like nausea, dizziness, dry mouth, sexual dysfunction and rise in blood pressure. Venlafaxine appears to demonstrate superior efficacy and higher rates of remission in severe depression as compared with either SSRI such as fluoxetine or tricyclic antidepressants. ${ }^{16}$ The efficacy of duloxetine is similar to that of the SSRI paroxetine and TCAs. 
Bupropion inhibits both norepinephrine and dopamine reuptake, has no direct action on the serotonin system. It is similar in efficacy to tricyclic antidepressants and SSRIs. Bupropion is associated with less nausea, diarrhea, somnolence and sexual dysfunction than are SSRIs and constitutes an effective alternative, or adjunctive therapy, for patients who do not have a response to SSRIs. ${ }^{17}$ Bupropion is effective in the management of smoking cessation and may be used as a first-line alternative to nicotine replacement therapy (NRT) and its action is said to be independent of its antidepressant activity.

\section{Nonselective norepinephrine-reuptake inhibitors:}

The tricyclic antidepressants like desipramine, nortriptyline and maprotilene block norepinephrine reuptake more potently than serotonin uptake. Even these are not really selective since they block $\alpha-1, \mathrm{H} 1$ and muscarinic receptors. ${ }^{18}$

\section{Selective serotonin reuptake inhibitors:}

SSRIs all share the property of blocking the action of the pre-synaptic serotonin reuptake pump, thereby increasing the amount of serotonin available in the synapse and increasing post synaptic serotonin receptor occupancy. Increased synaptic availability of serotonin stimulates a large number of post synaptic 5HT receptor types. Stimulation of $5-\mathrm{HT}_{3}$ and $5-\mathrm{HT}_{2 \mathrm{c}}$ receptors contributes to nausea and agitation or restlessness respectively. In the serotonin system, 5$\mathrm{HT}_{1}$ subtype auto receptors (type $1 \mathrm{~A}$ and 7 at raphe cell bodies and dendrites, type 1D at terminals) suppress serotonin neurons in the raphe nuclei of brain stem, inhibiting both tryptophan hydroxylase and neuronal release of serotonin. Repeated treatment leads to gradual down regulation and desensitization of auto receptor mechanisms over several weeks, particularly of $5-\mathrm{HT}_{1 \mathrm{D}}$ receptors at nerve terminals leading to increased pre-synaptic activity, production and release of serotonin. Additional secondary down regulation of postsynaptic $5-\mathrm{HT}_{2 \mathrm{~A}}$ receptors may contribute to antidepressant effects directly.

The antidepressant effects of SSRIs may not appear for three to six weeks after initiation of treatment. It is proposed that this delay in clinical response is due to gradual "down regulation" or decrease in some postsynaptic serotonin receptor types in response to the increased amount of synaptic serotonin available. This may lead to changes in cellular protein production and to subsequent effects on neuronal protection and development. ${ }^{19}$

SSRIs are considered as first line agents in the treatment of mild to moderate depression because of their relative safety and better acceptability. Their main advantage is that they produce little or no sedation, do not interfere with cognitive and psychomotor function or produce anticholinergic side effects. They do not cause postural hypotension, do not inhibit cardiac conduction and practically have no seizure precipitating propensity. They do not produce weight gain. Their predominant side effects are gastrointestinal: nausea (due to $5-\mathrm{HT}_{3}$ receptor stimulation). Increased incidence of epistaxis and ecchymosis has been reported due to interference with platelet functions. SSRIs may cause mania when used in patients with undiagnosed bipolar depression patients. These drugs can interact with the drugs which increase CNS serotonin activity like MAOIs, pethidine, two or more SSRIs etc. and may cause serotonergic syndrome. ${ }^{20}$

All SSRIs if stopped suddenly can produce withdrawal symptoms. Longer $\mathrm{t}_{1 / 2}$ agents like fluoxetine cause lesser incidence of these symptoms.

\section{Selective norepinephrine-reuptake inhibitors (NRIs):}

Reboxetine is a selective norepinephrinereuptake inhibitor with effectiveness similar to that of tricyclic antidepressants and SSRIs.

III. Mixed action newer agents-Atypical
antidepressants:

Atypical antidepressants act more selectively on 5-HT receptors subtypes as compared to older SSRIs. They also have low affinity for muscarinic, dopaminergic and $\mathrm{H}_{1}$ histaminic receptors resulting in few adverse reactions.

\section{Mirtazapine}

It is a tetracyclic antidepressant that works by its central pre-synaptic $\alpha_{2}$-adrenergic antagonist effects, which results in increased release of norepinephrine and serotonin. It is also a potent antagonist of 5- $\mathrm{HT}_{2}$ and 5$\mathrm{HT}_{3}$ serotonin receptors and $\mathrm{H}_{1}$ histamine receptors and a moderate peripheral $\alpha_{1}$-adrenergic and muscarinic antagonist. It does not inhibit the reuptake of norepinephrine or serotonin. It is proposed that the medication's antagonism of pre-synaptic $\alpha_{2}$-receptors and $5-\mathrm{HT}_{2 \mathrm{~A}}$ receptors leads to a significant increase in noradrenergic neurotransmission. This heightened adrenergic neurotransmission, in concert with mirtazapine's action of increasing serotonin release, is thought to be responsible for the medication's antidepressant effect. The adverse effects of mirtazapine are increase in appetite, weight gain and sedation. ${ }^{21}$

\section{Mianserin:}

It is a tetracyclic antidepressant which blocks pre-synaptic adrenergic $\left(\alpha_{2}\right)$ receptors and increases the turnover of norepinephrine in brain. Its use is restricted owing to its propensity to cause bone marrow suppression, seizures, sedation and liver dysfunction.

\section{Trazodone and Nefazodone:}

Nefazodone, a phenylpiperazine is structurally related to trazodone, have direct agonistic action at serotonin $5-\mathrm{HT}_{2 \mathrm{~A}}$ receptors and has serotonin reuptake blocking properties. Trazodone has weak inhibitory action on serotonin transport and nefazodone also have a minor effect on norepinephrine transport which may contribute to antidepressant and anxiolytic activity. Both drugs also may inhibit pre-synaptic 5- $\mathrm{HT}_{1}$ subtype auto-receptors to enhance neuronal release of serotonin, though they also exert partial-agonist effects on postsynaptic $5-\mathrm{HT}_{1}$ receptors. They also block cerebral $\alpha_{1}$ and $H_{1}$ receptors, contributing to its tendency to induce priapism and sedation respectively. Nefazodone 
appears to be useful in postpartum depression, severe depression and treatment resistant depression with anxiety. $^{22}$

\section{Tianeptine and amineptine:}

Tianeptine sodium and amineptine hydrochloride act by increasing (rather than inhibiting) the pre-synaptic reuptake of serotonin. They are efficacious in anxio-depressive states with psychosomatic symptoms and in endogenous depression. They cause anticholinergic side effects. Postural hypotension, conduction disturbances and arrhythmias can occur specially in patients with cardiac diseases. $^{23}$

\section{Agomelatine:}

It is the first melatonergic antidepressant, and has potent agonist effects at melatonin MT1 and MT2 receptors and has beneficial effects upon sleep disturbances. It also antagonizes the seretonergic 5$\mathrm{HT}_{2 \mathrm{C}}$ receptor, which in turn enhances release of dopamine and norepinephrine. The melatonergic and serotonergic actions both contribute to its antidepressant properties. $^{24}$ Agomelatine was approved for use in Europe in 2009 but is not approved in the United States.

\section{Augmenting or Adjunctive Drugs:}

Various medications used in conjunction with other antidepressants may help to augment the effect of antidepressants. They can also target different components of patient's symptoms (such as delusions) or help to prevent a switch to mania.

\section{A. Mood stabilizers:}

Patients with mood swings and a strong family history of bipolar disorder may meet criteria for bipolar II disorder and should be treated with a mood stabilizing drug such as lithium, valproate or lamotrigine.

I. Lithium: It alters cation transport across cell membrane in nerve and muscle cells and influences reuptake of serotonin and/or norepinephrine; second messenger systems involving the phosphatidyl-inositol cycle are inhibited; postsynaptic $D_{2}$ receptor supersensitivity is inhibited. Lithium is an anti-manic agent and, as a mood stabilizer, prevents the recurrence of mania or depression. It may be superior to placebo for bipolar depression but not for major depression.
Lithium is an effective augmenting agent, and the condition of roughly half the patients who do not have a response to a single antidepressant improves when lithium is added. ${ }^{25}$

II. Lamotrigine: It is an anticonvulsant and triazine derivative which inhibits the release of glutamate (an excitatory amino acid) and inhibits voltage sensitive sodium channels, which stabilises neuronal membranes. Lamotrigine has weak inhibitory effect on the $5-\mathrm{HT}_{3}$ receptor; in vitro inhibits dihydrofolate reductase. It is used as an augmenting agent in major depressive disorder and for treating and preventing depressive relapse in bipolar disorder. $^{26}$

III. Valproic acid: Causes increased availability of gamma-aminobutyric acid (GABA), an inhibitory neurotransmitter, to brain neurons or may enhance the action of GABA or mimic its action at postsynaptic receptor sites. Divalproex or valproate may prevent a recurrence of bipolar depression. ${ }^{27}$

\section{B. Antipsychotic agents:}

Treatment guidelines from the American Psychiatric Association published in 2000 recommends that patients with psychotic depression should receive the combination of an antipsychotic plus antidepressant, or should be treated with ECT. Typical antipsychotic agents (e.g., chlorpromazine, fluphenazine and haloperidol) block the dopamine $\mathrm{D}_{2}$ receptor, whereas "atypical" antipsychotic agents (e.g., clozapine, olanzapine, risperidone, quetiapine, ziprasidone and aripiprazole), like nefazodone, act as 5- $\mathrm{HT}_{2 \mathrm{~A}}$ antagonists. Atypical antipsychotic drugs are also used for treatment resistant major depression and bipolar depression. $^{28}$

\section{Thyroid supplement:}

Triiodothyronine $\left(\mathrm{T}_{3}\right)$ has been used as augmentation therapy in patients who have not responded to initial treatment with antidepressants. In Level 3 of the Sequenced Treatment Alternatives to Relieve Depression (STAR*D) trial, triiodothyronine as well as Lithium were better tolerated. Trials on the use of $\mathrm{T}_{3}$ in combination with SSRI for the initial treatment of depression, as enhancement therapy to improve initial response rates, have produced contradictory findings. ${ }^{29}$ 
Table 1: Dosing and adverse effect profile of antidepressant medications. ${ }^{30}$

\begin{tabular}{|c|c|c|c|}
\hline Name & \multirow{2}{*}{$\begin{array}{l}\text { Daily } \\
\text { Dose } \\
\text { (mg) }\end{array}$} & \multirow{2}{*}{ Side Effects } & \multirow{2}{*}{ Comments } \\
\hline SSRIs & & & \\
\hline $\begin{array}{l}\text { Fluoxetine (Prozac) } \\
\text { Sertraline (Zoloft) } \\
\text { Paroxetine (Paxil) } \\
\text { Fluvoxamine (Luvox) } \\
\text { Citalopram (Celexa) } \\
\text { Escitalopram (Lexapro) }\end{array}$ & $10-80$ & $\begin{array}{l}\text { Headache; nausea and other GIT } \\
\text { effects; jitteriness, insomnia,sexual } \\
\text { dysfunction; can affect plasma levels } \\
\text { of other medicines (except sertraline); } \\
\text { akathisia rare. }\end{array}$ & $\begin{array}{l}\text { Once daily dosing, usually in } \\
\text { A.M.; fluoxetine has very long } \\
\text { half-life; must not be combined } \\
\text { with MAOIs. }\end{array}$ \\
\hline \multicolumn{4}{|l|}{ TCAs } \\
\hline $\begin{array}{l}\text { Amitriptyline (Elavil) } \\
\text { Nortriptyline (Pamelor) } \\
\text { Imipramine (Tofranil) } \\
\text { Desipramine } \\
\text { (Norpramin) } \\
\text { Doxepin (Sinequan) } \\
\text { Clomipramine (Anafranil) }\end{array}$ & $\begin{array}{l}150-300 \\
50-200 \\
150-300 \\
150-300 \\
\\
150-300 \\
150-300\end{array}$ & $\begin{array}{l}\text { Anticholinergic (dry mouth, } \\
\text { tachycardia, constipation, urinary } \\
\text { retention, blurred vision); sweating; } \\
\text { tremor; postural hypotension; cardiac } \\
\text { conduction delay; sedation; weight } \\
\text { gain. }\end{array}$ & $\begin{array}{l}\text { Once daily dosing, usually qhs; } \\
\text { blood levels of most TCAs are } \\
\text { available; can be lethal in O.D. } \\
\text { (lethal dose-2g); nortriptyline } \\
\text { best tolerated, especially by } \\
\text { elderly. }\end{array}$ \\
\hline $\begin{array}{l}\text { Mixed norepinephrine/ } \\
\text { serotonin reuptake inhibitors } \\
\text { Venlafaxine (Effexor) }\end{array}$ & $75-375$ & $\begin{array}{l}\text { Nausea; dizziness; dry mouth; } \\
\text { headaches; increased blood pressure, } \\
\text { anxiety and insomnia; lethality. }\end{array}$ & $\begin{array}{l}\text { Bid-tid dosing (extended } \\
\text { release available); lower } \\
\text { potential for drug interactions } \\
\text { than SSRIs; contraindicated } \\
\text { with MAOIs. }\end{array}$ \\
\hline Mirtazapine (Remeron) & $15-45$ & $\begin{array}{l}\text { Somnolence; weight gain; neutropenia } \\
\text { rare. }\end{array}$ & Once daily dosing. \\
\hline $\begin{array}{ll}\text { Mixed-action } & \text { drugs } \\
\text { Bupropion (Wellbutrin) } & \end{array}$ & $250-450$ & $\begin{array}{l}\text { Jitteriness; flushing; seizures in at-risk } \\
\text { patients; anorexia; tachycardia; } \\
\text { psychosis. }\end{array}$ & $\begin{array}{l}\text { Tid dosing, but sustained } \\
\text { release also available; fewer } \\
\text { sexual side effects than SSRIs } \\
\text { or TCAs; may be useful for } \\
\text { adult ADD. }\end{array}$ \\
\hline Nefazodone (Serzone) & $300-600$ & $\begin{array}{l}\text { Sedation; headache; dry mouth; } \\
\text { nausea; constipation. }\end{array}$ & $\begin{array}{l}\text { Once daily dosing; no effect on } \\
\text { REM sleep unlike other } \\
\text { antidepressants. }\end{array}$ \\
\hline Amoxapine (Asendin) & $200-600$ & Sexual dysfunction. & $\begin{array}{l}\text { Lethality in overdose; EPS } \\
\text { possible. }\end{array}$ \\
\hline \multicolumn{4}{|l|}{ MAOIs } \\
\hline $\begin{array}{l}\text { Phenelzine (Nardil) } \\
\text { Tranylcypromine (Parnate) } \\
\text { Isocarboxazid (Marplan) }\end{array}$ & $\begin{array}{l}45-90 \\
20-50 \\
20-60\end{array}$ & $\begin{array}{l}\text { Insomnia; hypotension; anorgasmia; } \\
\text { weight gain; hypertensive crisis; } \\
\text { tyramine cheese reaction; lethal } \\
\text { reactions with SSRIs; serious reactions } \\
\text { with narcotics. }\end{array}$ & $\begin{array}{l}\text { May be more effective in } \\
\text { patients with atypical features } \\
\text { or treatment refractory } \\
\text { depression. }\end{array}$ \\
\hline
\end{tabular}

\section{CURRENT STATUS OF ANTIDEPRESSANTS:}

The pharmacological therapies in the treatment of depression bring acute and sustained remission only in a minority of patients. For example recent effectiveness trials have shown that only one out of the three depressed out-patients receiving first step treatment of SSRI achieved remission from depressive symptoms. Other large multicenter trials in chronically depressed out-patients confirm the modest remission rates. A recent meta-analytic study of randomized controlled trial (RCT) data by Kirsch et al. effectively concluded that the new antidepressant drugs are either no better than placebos or only as effective as placebos. In 2008 Turner et al. published a study in the New England Journal of Medicine showing that the scientific journal literature on antidepressants was biased towards "favourable" results. ${ }^{31}$ There is a dire need for developing new effective drugs for the treatment of depression.

Neutraceuticals have started gaining much attention in today's world. Many natural products are believed to have role in treating diseases and promotion of health. The role of neutraceuticals in the treatment of depression is also being evaluated. ${ }^{32}$ The small amount of controlled clinical research that has been done is encouraging with regard to the efficacy of some neutraceuticals that have shown benign side effect profiles and limited toxicity. In fact, the most commonly used neutraceuticals appear to be better tolerated than the more standard, conventionally used antidepressants, such as SSRIs. Some of these nutritional supplements can be used in patients who have achieved only partial treatment response to standard antidepressant medications and may offer additional clinical benefit without increasing the side 
effect burden. Studies have shown the efficacy of Sadenosylmethionine (SAMe), St. John's Wort (SJW) and omega-3 fatty acids in the treatment of depression. ${ }^{33}$

\section{REFERENCES}

1. Depression. WHO; [cited 25 May 2011]. Available from: http://www.who.int/mental_health/management/depression/de finition/en/.

2. Madhav SM. Epidemiological study of prevalence of mental disorders in India. Indian Journal of Community Medicine. 2001 Oct-Dec; 26 (4):198-200.

3. American Psychiatric Association. DSM-IV TR. Washington, D.C. APA; 2000 with permission as reproduced in Sadock BJ, Sadock VA, Ed., Synopsis of psychiatry, $9^{\text {th }}$ ed., New York: Lippincott Williams \& Wilkins; 2003. p.542.

4. HL Sharma, KK Sharma. Antidepressant and antimanic drugs, Priniciples of Pharmacology, $2^{\text {nd }}$ edition, Paras publication. 2011: 461.

5. Baldessarini RJ. Drug therapy of depression and anxiety disorders. In: Brunton LL, Lazo JS, Parker KL, editors. Goodman \& Gilman's: The Pharmacological Basis of Therapeutics. New York: McGraw Hill; 2006. p. 431.

6. Kuhn R. The treatment of depressive states with G 22355 (Imipramine hydrochloride). Am J Psychiatry. 1958; 115(5):459-464.

7. Baldessarini RJ. Drug therapy of depression and anxiety disorders. In: Brunton LL, Lazo JS, Parker KL, editors. Goodman \& Gilman's: The Pharmacological Basis of Therapeutics. New York: McGraw Hill; 2006; p. 441-442.

8. Mann JJ. The medical management of depression. N Engl J Med. 2005; 353(17):1819-1834.

9. Battista CD. Antidepressant agents. In: Katzung BG, Masters SB, Trevor AJ, editors. Basic and Clinical Pharmacology. New Delhi: Tata McGraw-Hill; 2009.p.524.

10. Thase ME, Mallinger AG, McKnight D, Himmelhoch JM. Treatment of Imipramine-resistant recurrent depression, IV: A double-blind crossover study of tranylcypromine for anergic bipolar depression. Am J Psychiatry. 1992; 149(2):195-8.

11. Quitkin FM, Stewert JW, McGrath PJ, Tricamo E, Rabkin JG, Ocepek-Welikson K, et al. Columbia atypical depression. A subgroup of depressives with better response to MAOI than to tricyclic antidepressants or placebo. Br J Psychiatry Suppl. 1993; (21):30-4.

12. Stahl SM. Classical Antidepressants, Serotonin Selective Reuptake Inhibitors and Noradrenergic Reuptake Inhibitors. In: Essential Psychopharmacology. Cambridge: Cambridge University Press; 2000.p.218-22.

13. Baldessarini RJ. Drug therapy of depression and anxiety disorders. In: Brunton LL, Lazo JS, Parker KL, editors. Goodman \& Gilman's: The Pharmacological Basis of Therapeutics. New York: McGraw Hill; 2006. p. 438-442.

14. Potter WZ. Bipolar depression: specific treatments. J Clin Psychiatry. 1998; 59 Suppl 18:30-6.

15. Treatment of depression-newer pharmacotherapies. Evidence report/technology assessment no.7. Washington D.C: Agency for Health Care Policy and Research; March 1999. AHCPR publication no. 99-E013.

16. Smith D, Dempster C, Glanville J, Freemantle N, Anderson I. Efficacy and tolerability of venlafaxine compared with selective serotonin reuptake inhibitors and other antidepressants: a meta-analysis. Br J Psychiatry. 2002; 180:396-404.

17. DeBattista C, Solvason HB, Poirier J, Kendrick E, Schatzberg AF. A prospective trial of bupropion SR augmentation of
SOURCE OF SUPPORT: Nil

CONFLICT OF INTEREST: No partial and non-responders to serotonergic anti-depressants. J Clin Psychopharmacol. 2003; 23(1):27-30.

18. Stahl SM. Classical Antidepressants, Serotonin Selective Reuptake Inhibitors and Noradrenergic Reuptake Inhibitors. In: Essential Psychopharmacology. Cambridge: Cambridge University Press; 2000.p.234-35.

19. Reid IC, Stewart CA. How antidepressants work: new perspectives on the pathophysiology of depressive disorder. Br J Psychiatry. 2001; 178:299-303.

20. Baldessarini RJ. Drug therapy of depression and anxiety disorders. In: Brunton LL, Lazo JS, Parker KL, editors. Goodman \& Gilman's: The Pharmacological Basis of Therapeutics. New York: McGraw Hill; 2006. p. 448-49.

21. Gorman JM. Mirtazapine: clinical overview. J Clin Psychiatry. 1999; 60 suppl17:9-13; discussion 46-8.

22. Taylor FB, Prather MR. The efficacy of nefazodone augmentation for treatment resistant depression with anxiety symptoms or anxiety disorder. Depress Anxiety.2003; 18(2):83-8.

23. Sweetman SC, editor. Martindale. The Complete Drug Referance. London: Pharmaceutical press; 2009.

24. Kasper S, Hajak G, Wulff K, Hoogendijk WJ, Montejo AL, Smeraldi E, et al. Efficacy of the novel antidepressant agomelatine on the circadian rest-activity cycle and depressive and anxiety symptoms in patients with major depressive disorder: a randomized, double-blind comparison with sertraline. J Clin Psychiatry. 2010; 71(2):109-20.

25. Bauer M, Dopfmer S. Lithium augmentation in treatment resistant depression: meta-analysis of placebo controlled studies. J Clin Psyhopharmacol. 1999; 19(5):427-34.

26. Yatam LN. Newer anti-convulsants in the treatment of bipolar disorder. J Clin Psychiatry. 2004; 65 suppl10:28-35.

27. Bowden CL, Calabrese JR, McElroy SL, Gyulai L, Wassef A, Petti $\mathrm{F}$ et al. A randomized, placebo controlled 12 months trial of divalproex and lithium in treatment of out-patients with bi-polar I disorder. Divalproex maintenance study group. Arch Jen Psychiatry. 2000; 57(5):481-89.

28. Keck PE. Jr. Bipolar depression: a new role for atypical antipsychotics? Bipolar Disord. 2005; 7 Suppl 4:34-40

29. Nierenberg AA, Fava M, Trivedi MH, Wisniewski SR, Thase ME, McGrath PJ, et al. A comparison of lithium and T(3) augmentation following two failed medication treatments for depression: a STAR*D report. Am J Psychiatry. 2006; 163(9):1519-30; quiz 1665.

30. Barton F, Haynes, Fauci AS. Mental Disorders. Harrison's Principles of Internal Medicine, 17th edition. USA, McGraw Hill. 2008: 2712.

31. Turner EH, Matthews AM, Linardatos E, Tell RA, Rosenthal R. Selective publication of antidepressant trials and its influence on apparent efficacy. N Engl J Med. 2008; 358(3):252-60.

32. Targum SD, Mischoulon D. The status of nutraceuticals for the treatment of depression. Psychiatry (Edgmont). 2009; 6(9):46-8.

33. Jazayeri S, Tehrani-Doost M, Keshavarz SA, Hosseini M, Djazayery A, Amini H, et al. Comparison of therapeutic effects of omega-3 fatty acid eicosapentaenoic acid and flouxetine, separately and in combination, in major depressive disorder. Aust N Z J Psychiatry. 2008; 42(3):192-8. 